\title{
REVIEW
}

Open Access

\section{An unprecedented COPA gene mutation in two patients in the same family: comparative clinical analysis of newly reported patients with other known COPA gene mutations}

\author{
Anjali Patwardhan ${ }^{1 *}$ (D) and Charles H. Spencer ${ }^{2}$
}

\begin{abstract}
Introduction: The COPA syndrome is a newly recognized monogenic, autosomal dominant autoimmune disease presenting mostly presenting in childhood. Clinical features include inflammation of the lungs, kidneys, and joints. Approximately twenty-six patients with COPA syndrome worldwide have been investigated all originating from eight families. Patients with this syndrome exhibit heterozygous monogenic missense mutations in the WD40 domain. This domain is a functionally-significant area of the alpha subunit of coatomer-associated protein (COPa) which encodes the coat protein complex I (COPI). The COPI dysfunction is also associated with autoantibody expansion. We report two patients with COPA syndrome.
\end{abstract}

Methods: All testing and molecular genetic analysis were performed after obtaining the informed consent of both the patient and parents. A retrospective chart review was carried out on both the patients. Demographic, clinical and laboratory findings were abstracted from outpatient and inpatient encounters. Pulmonary function tests (PFTs), chest computed tomography (CT) scans, and lung biopsy histopathology reports were also reviewed and summarized.

Results: The index case and the father of the child both demonstrated a unique inflammatory pulmonary, arthritis, and renal disease triad starting in early childhood including pulmonary hemorrhage. The two patients had a novel COPA mutation previously undescribed.

Conclusions: To date, only four pathological, genetic mutations have been reported that are compatible with COPA syndrome. We here report two patients with COPA syndrome within the same family with a novel COPA gene mutation different than the heterozygous monogenic missense mutations in the WD40 domain and distinct from the clinical phenotypes reported in the literature so far.

Keywords: Autoimmunity, COPA syndrome, Interstitial lung disease, Arthritis, Pulmonary hemorrhage, Alveolitis

\footnotetext{
* Correspondence: doctoranjali@hotmail.com

'University of Missouri School of Medicine, 400 Keene Street, Columbia, MO

65201, USA

Full list of author information is available at the end of the article
}

(c) The Author(s). 2019 Open Access This article is distributed under the terms of the Creative Commons Attribution 4.0 International License (http://creativecommons.org/licenses/by/4.0/), which permits unrestricted use, distribution, and reproduction in any medium, provided you give appropriate credit to the original author(s) and the source, provide a link to the Creative Commons license, and indicate if changes were made. The Creative Commons Public Domain Dedication waiver (http://creativecommons.org/publicdomain/zero/1.0/) applies to the data made available in this article, unless otherwise stated. 


\section{Introduction}

The Coatomer Protein, Subunit Alpha (COPA) gene is mapped on the chromosome one location 1q23.2 [1]. The COPA protein is a $160-\mathrm{kD}$ molecule that is expressed at normal levels in patients with gene mutations such that immune dysregulation is the functional consequence of the mutation [2].

In the most extensive series to date of 30 individuals with known mutations attributable to COPA syndrome, nine subjects were asymptomatic, suggesting variable/incomplete penetrance [3]. The COPA gene is expressed in immune as well as non-immunologic cells but is predominantly present in the microsomal and cytosolic fractions, and is absent in nucleus. Patients with this syndrome exhibit heterozygous, monogenic missense mutations in the WD40 domain (a functionally-significant area) of the alpha subunit of coatomer-associated protein $(\mathrm{COP} \alpha)$ which encodes the coat protein complex-I (COPI). The COPI is an integral part of the intracellular carrier complex in protein transport mechanism from the Golgi complex to the endoplasmic reticulum (ER).

To explain the genetics better, the COPA gene's Cytogenetic Location is positioned within the long (q) arm of chromosome-1 at 23.2(1q23.2), and the molecular location is at the base pairs $160,288,587$ to $160,343,564$ on chromosome-1. The protein transport between the endoplasmic reticulum and the Golgi bodies is mediated by the coat proteins (COPs) which operate as subunits in a complex structure called coatomer coat protein complex-1, in all eukaryotic cells. The seven subunits of the coatomer complex are named as (alpha, beta, betaprime, gamma, delta, epsilon, and zeta)-COP. In humans, alpha-COP protein is encoded by coatomer protein complex subunit alpha (COPA gene), which is very similar to the alpha subunit of the coatomer complex in yeast cells known as RET1P, used in COPA gene research. The defective COPI function due to gene mutation leads to impaired retrograde Golgi-to-ER protein transport which in turn leads to compensatory, but ineffective protein translation, followed by ER stress and cellular autophagy [4]. ER stress causes the release of the pro-inflammatory cytokines (IL-1 $\beta$ and IL-6) that in turn, lead to an increase in the number of $\mathrm{T}$-helper type 17 (TH17) cells $[1-3,5,6]$. The CD4 (+) T cells derived from COPA syndrome patients show skewing toward a preferential TH17 response and the changes in T cell populations are believed to foster immune dysregulation and autoimmunity [5]. Besides, COPI dysfunction is also associated with autoantibody expansion [3]. Volpi and collaborators have shown the presence of an interferon activation signature in the peripheral blood of a COPA patient [7].

The COPA syndrome is thus a newly recognized Mendelian monogenic, autosomal dominant autoimmune disease presenting usually in childhood, and characteristically associated with the constellation of defined and specific clinical features. It is also known as HEP-COP and Autoimmune Interstitial Lung, Joint, and Kidney disease (AILJK). The AILJK term may be misleading as the interstitial lung disease is not necessarily present in all cases. Twenty-six patients with COPA syndrome have been investigated worldwide originating from eight families [3, 5]. To date, only four pathological, genetic mutations have been reported that result in the COPA syndrome (Table 1). We report two COPA syndrome patients from the two generations in the same family (son and father) with a novel gene mutation in the COPA gene and a different clinical presentation, distinct from the clinical phenotypes reported in the literature. To our knowledge, this gene mutation and clinical syndrome have not been reported before.

\section{Materials and methods}

All testing and molecular genetic analysis were performed after obtaining the informed consent of both the patient and parents. The protocol and data extraction from the medical records was approved by the Institutional Review Boards of the University of Missouri (approval number: 239766. Project \#: IRB \#2012122 $\mathrm{MU})$. The index patient was diagnosed with COPA syndrome, and subsequently, his father was tested for COPA gene mutation because he had a history of recurrent pulmonary hemorrhage as a child. The father also tested positive for same gene mutation as the index case. The retrospective chart review was carried out on both the patients. Demographic, clinical and laboratory findings were abstracted from outpatient and inpatient encounters, and pulmonary function tests (PFTs), chest computed tomography (CT) scans, and lung biopsy histopathology reports were also reviewed and summarized.

\section{Results}

Index case (Fig. 1 and Fig. 2)

Our index case (IC), a Caucasian- Hispanic 2 years eight-months-old male, presented to the emergency room with a chronic cough, fatigue, increasing pallor and recurrent episodes of shortness of breath. He was diagnosed with hypochromic microcytic severe chronic anemia (hemoglobin $2.7 \mathrm{~g} / \mathrm{dl}$ ) and received a blood transfusion. He was admitted to the pediatric intensive care unit (PICU) and required mechanical ventilation after developing acute respiratory distress and failure. His laboratory tests revealed elevated inflammatory markers (ESR, CRP, IgG, and platelets), elevated reticulocyte count (5\%). Bilirubin, haptoglobin, and G6PD testing were normal. An extensive work-up seeking an infectious etiology was negative. No source could be identified explaining the extensive blood loss. 
He had a history of chronic eczema, and three episodes of 'afebrile pneumonia' in the past. The first episode was at age 6 months which were empirically treated with antibiotics. Due to poor growth and development, he was evaluated for cystic fibrosis, immunodeficiency, hemolytic disorder, infections, and malignancy, but all such diagnostic efforts were negative. Serum ferritin levels were normal, but low normal iron saturation and high soluble transfer receptor levels were found. He appeared to make an uneventful recovery at the time and was discharged.

Two months after discharge, he presented again to urgent care with shortness of breath and was found to have the hemoglobin of $7.9 \mathrm{~g} / \mathrm{dL}$. His general physical examination was positive for grade-two clubbing in all the extremities. He was positive for Harrison's sulcus, pectus carinatum, pallor, cyanosis, poor oxygen saturation but normal blood pressure. He was admitted to PICU again. His CT chest showed bilateral diffuse ground-glass opacities without focal consolidation, interstitial infiltrates. The possibility of pulmonary hemorrhage was considered.

At this point, he also tested positive for ANA (1: 1280 speckled), and ANCA (1:2560-1:5120). He had variable positives for Anti MPO (10.6 to 106 RLU. normal range $<=20.0)$, Anti PR3 $(<2.3$ RLU. normal range $<=20.0$ ), Anti RNP, Anti SSA/RO, Anti SSB/LA, Anti Smith, Anti-double-stranded DNA, i.e. all Extractable Nuclear Autoantibodies (ENA) antibodies. He had a moderate elevation of inflammatory markers (ESR, CRP, platelets and immunoglobulin G) at the time. The ESR and CRP values and clinical flares, though, did not coincide with ANCA peaks.

He was negative for rheumatoid factor, and anti-CCP autoantibody and his urinalysis and kidney function tests were normal. $\mathrm{He}$ also tested negative for celiac diseases and cystic fibrosis. His bronchoalveolar lavage (BAL) fluid was Cloudy -tinged with blood and cell count of BAL fluid was $5262 / \mathrm{mcL}$ (WBC-2125/mcl, red cells of $3137 / \mathrm{mcL}$ ). The BAL fluid was negative for any infective etiology (bacterial, viral or fungal). Histoplasma antigen was negative in urine and BAL. The left lung wedge biopsy was consistent with resolving pulmonary capillaritis. Histopathologic features included frequent hemosiderin-laden macrophages, extravasation of red blood cells, interstitial inflammation, capillaritis, and features of lymphocytic bronchiolitis, i.e. diffuse pulmonary lymphoid hyperplasia. There was a mild widening of alveolar ducts and minimal distension of air spaces at the periphery, suggesting a component of small airway obstruction.

He was initially treated with intravenous pulse methylprednisolone $250 \mathrm{mg}$ for three consecutive days followed by oral steroids. The oral steroids were tapered over time to $5 \mathrm{mg} /$ day as maintenance therapy with
Methotrexate (up to $12 \mathrm{mg} / \mathrm{M} 2 /$ week). He did not respond to methotrexate and then azathioprine. He continued to have episodes of shortness of breath (SOB), decreasing hemoglobin and pulmonary hemorrhages at the same frequency as before and had several pediatric intensive care unit (PICU) admissions. On one occasion when spirometry could be performed successfully, the results showed a presence of partially reversible small airways obstruction mixed with some restrictive patterns. His flow rates were: FVC $-1,1 \mathrm{~L}$ (96\% of predicted, $100 \%$ of predicted post-treatment), FEV1-0.94 (121\% of predicted, $117 \%$ of predicted after treatment), FEV1/ FVC \%-85 of predicted, and post-treatment $79 \%$ of predicted. Rituximab was not approved for use by his insurance company. He was then started on mycophenolate mofetil (MMF) $30 \mathrm{mg} / \mathrm{kg} /$ day in two divided doses along with the low dose oral steroids. He showed a positive response as he has had no pulmonary hemorrhages and PICU/hospital admissions since. Three months into the MMF therapy, he was tested for COPA gene mutation which returned positive. His brother and father were also tested for COPA gene mutations. The gene test for the father returned as positive for the same gene mutation as the index case.

\section{The father of the index case (Fig. 1 and Fig. 2)}

He was a 29 years old Caucasian male. He first presented with chronic respiratory insufficiency (poor oxygen saturation), exertional dyspnea, recurrent coughing, breathlessness and polycythemia (hemoglobin of $15.8 \mathrm{~g} /$ $\mathrm{dl}$, hematocrit of $48.2 \%$ and red cell count of $5.79 \mathrm{mil} /$ cu.mm). He had clubbing in all the fingers and toes and worsening respiratory symptoms. He was seen by a cardiologist, and a cardiac etiology was ruled out for clubbing. He had a normal EKG and Echocardiogram.

Past history revealed that he had his first admission to PICU at 7 years of age which was for breathing difficulties, cyanosis, and low oxygen saturation, and chronic progressive cough. At that time, his CT chest showed diffuse ground-glass opacities and significantly prominent interstitial lung markings, as well as mild hyperinflation of peripheral air spaces with occasional cyst formations. His open lung biopsy at the time showed diffusely distended alveoli, hemosiderin-laden macrophages, and extravasated red blood cells. He had parabronchial lymphoid infiltrates with prominent germinal centers in his lung histology. Direct immunofluorescence studies on the biopsy material showed $1+\mathrm{C} 3$ complement lining some cystic spaces which were considered to be nonspecific. No antibodies to basement membranes or Ig-G, Ig-M, Ig-A, C1q, fibrinogen or properdin was detected on immunofluorescence staining. He had moderately elevated inflammatory markers (ESR, CRP, IgG, platelets). He tested positive for ANA (1:1280 
homogenous) and ANCA. He was negative for ENA, rheumatoid factor (RF) and anti-CCP. Extensive testing for infections was negative.

$\mathrm{He}$ required artificial ventilation and pulse methylprednisolone on admission for immediate control of his symptoms and responded well. In the course of his disease, he received several cycles of pulse steroids followed by moderate to low dose steroids for maintenance at an ongoing basis up until the age of 12 years. He did show continuing patterns of moderate elevations in inflammatory markers during his ongoing flares over time but his they did not seem to coincide with ANCA peaks every time. He was given a diagnosis of idiopathic pulmonary hemosiderosis at the time.

Hydroxychloroquine was added to his low dose steroid maintenance therapy later which he continued to take up until 18 years. He lost to follow up for 8 years. As per his records from childhood, he had several episodes of transient arthralgias with intermittent brief morning stiffness but was never diagnosed with arthritis. He never had abnormalities in the blood pressure, urine analysis or renal function tests. He never had hemoptysis. At 18 years of age, his DEXA scan for bone density showed decreased lumbar spine and whole-body bone density (Z-score at both the areas was -2.6 ). The PFT at age 7 , at the time of his first major pulmonary hemorrhage, showed vital capacity $(\mathrm{VC})=88 \%$ of predicted, FEV $1=69 \%$ of predicted, FEV $1 / \mathrm{FVC}=70 \%$ of predicted and FEF $25-75$ (53\% of predicted).

Initially, the bronchodilators failed to improve his lung volumes, but after a few years, he did show some intermittent response to bronchodilators. His lung volumes in 2008 showed FEV-1 of 2.971 (72\% predicted), FVC was $4.07 \mathrm{l}$ ( $84 \%$ predicted), total lung capacity was $81 \%$ of predicted, and DLCO was $62 \%$. His serial plethysmography results revealed air trapping with increased residual volumes and residual volumes over total lung capacity ratios. He required intermittent home oxygen therapy several times for poor exercise tolerance and frequent desaturations up until the age of 12 years.

After 8 years of lost follow up, he presented at the age of 26 years with severe erosive polyarthritis involving small and large joints. He was initially treated with etanercept $(50 \mathrm{mg} /$ week) and methotrexate $(20 \mathrm{mg} /$ week $)$ but failed treatment. Etanercept was replaced with 40 $\mathrm{mg}$ of adalimumab subcutaneous every other week which he is still taking. His last PFT in 2016 showed restrictive patterns with FEV1-65\% of predicted and FEV$70 \%$ of predicted No DLCO not available. His CT chest on July 2018 showed nodular thickening along the right major fissure measuring up to $6 \times 3 \mathrm{~mm}$ with an ovoid shape and well-circumscribed margins, possibly a intrapulmonary lymph node. The lung bases showed multifocal reticular fibrotic changes with areas of bronchiectasis: mild centrilobular and subpleural emphysema. He did not have a positive family history of other lung, kidney, or autoimmune inflammatory arthritis problems. There was no family history of autoimmune diseases. He has two older siblings who are well and healthy suggesting he may have a de-novo mutation.

Next Generation sequencing was performed for genetic testing in our cases. The two separate incidences of the c.722A > C p, Glu241Ala mutation in 2 affected individuals and its absence in normal sibling/family members and a large number of genomes/exomes in publically available genome Aggregation Database supports its pathogenetic role in the disease occurrence $[7,9,10]$.

This novel mutation in both the cases is likely to be pathogenetic according to the databases but function studies have not been taken as yet. Based on the available information, the most compatible inheritance model in our cases appears to the authors to be autosomal dominant, since two males in subsequent generations were affected with the same disease, and no female carriers were identified.

\section{Discussion and literature review}

The description of COPA syndrome in this article is based on the up to date published literature and information available on this disease. The COPA Syndrome is considered a TH17-associated autoimmuneautoinflammatory disease but the relationship seems to be complex. The other TH17-associated diseases (psoriasis and inflammatory bowels diseases) are not reported as commonly as expected co-morbidities in COPA Syndrome patients [5]. One of the other reported COPA syndrome patients developed systemic lupus erythematosus and macrophage activation syndrome in the course of the disease (Table 1). The ER-stress and upregulation of TH17 cell population are already known to have the

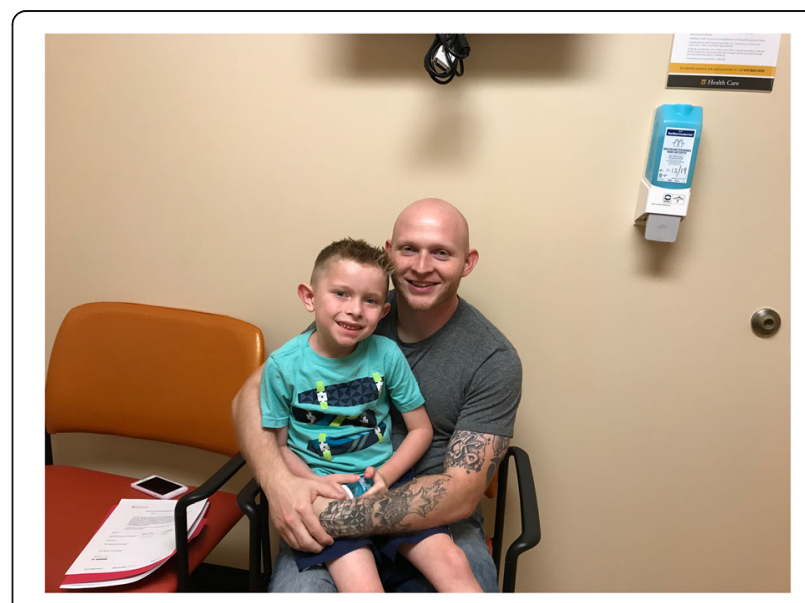

Fig. 1 Index case and his father 


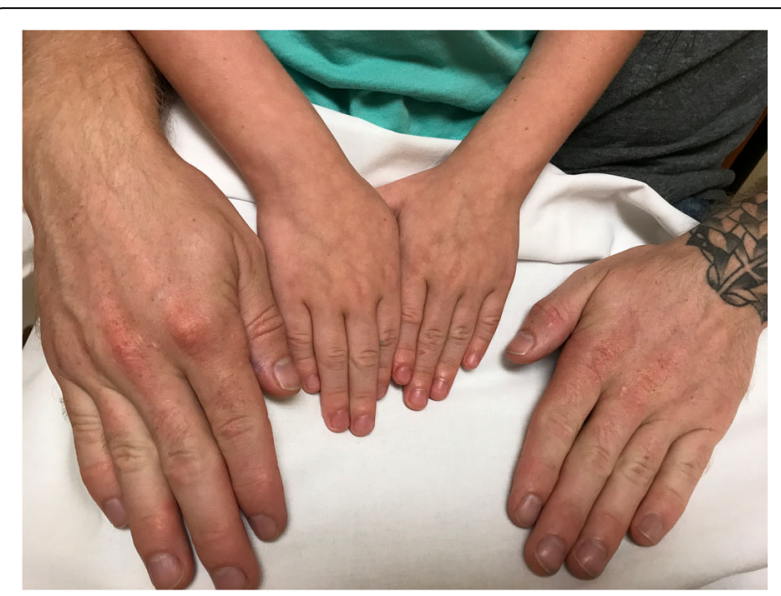

Fig. 2 Index case and his father. Both the patients had clubbing of their fingernails very early on in the diseases process

causal relationship with interstitial lung disease and autoimmunity [11-15].

Most cases of COPA syndrome are familial but denovo mutations are also reported. A female predominance appears to exist, and the majority of patients reported are caucasian, and a remaining minority of patients had been Asians. Organs that are known to be involved are lungs, joints, and kidney but lung inflammation is believed to be the key prognostic factor. Mostly, the pulmonary or/and joint inflammation had been the presenting symptoms, but pulmonary and joint diseases were not necessarily always seen to go hand in hand. The renal involvement is mostly reported late in the disease course. Most patients presented during childhood. In the largest reported series, $76 \%$ of patients presented before their fifth birthday [3]. The most common reported presenting symptoms are arthralgia/ arthritis, cough and tachypnea, hemoptysis, shortness of breath and more common than not, life-threatening pulmonary hemorrhage requiring intensive care and artificial ventilation [5].

The less common presentation was insidious onset with fatigue, cough, anemia due to unrecognized pulmonary hemorrhage, and arthralgias. Each specific gene mutation does not appear to predict the exact same clinical phenotype and disease course but may help in determining the prognosis and outcomes broadly as we learn more. An example is the p. Glu241Lys gene mutation from the Watkin et al. series and the Jensson et al. $[3,4]$ series did not have a similar disease presentation and course and showed a significantly different phenotype. In all reported series, the COPA syndrome patients showed only symptomatic and a partial response to immunosuppression and lung disease progressed over time despite chronic immunosuppressive treatment. With the current level of disease understanding, it is difficult to predict which patients may require a lung transplant in the future.

\section{Comparative analysis of different case series [Tables 1, 2, 3 and 4] \\ Autoantibody profile}

The information on the full spectrum of autoantibodies in COPA syndrome is still growing. In reported series, most patients were positive for antinuclear antibody (ANA) with titers measured as high as 1:1280 (indirect immunofluorescence). The majority of patients had positive anti-neutrophil cytoplasmic antibody (cANCA)/perinuclear antineutrophil cytoplasmic antibody (pANCA) and rheumatoid factor antibodies (RF). The other antibodies such as anti-myeloperoxidase antibodies (MPO), anti-proteinase-3 antibodies (PR3) were not performed in all the COPA syndrome patients but were positive in a small fraction of patients (Table 3). The presence and titers of antibodies showed titer-variations with time and disease activity but not enough evidence to use them as disease- activity biomarkers for monitoring the therapy. However, with our limited understanding of the syndrome, no single autoantibody has yet emerged as a biomarker of disease activity, disease severity or diseasedamage. Patients also often had elevated serum inflammatory markers including C-reactive proteins (CRP), immunoglobulin-G titer and erythrocyte sedimentation rate (ESR) which seems to better correlate with the disease activity [1]. The COPA patients mostly had normal white cell counts and differential white cell counts.

\section{Pulmonary disease}

Pulmonary hemorrhage and interstitial lung disease are common in several autoimmune diseases and not just COPA syndrome. The question remains if they all share the same or similar mechanisms for pulmonary inflammation. An immunologic finding triggering autoimmunity and inflammation consistently observed in COPA patients is the increased expression of cytokines IL-1 $\beta$, IL-6, and IL-23 which in turn upregulates TH17 cells with the reduction in TH1 cells in the affected tissues. The mechanism of pulmonary inflammation in COPA patients does not appear to be the same as in ANCA-associated vasculitis syndrome patients, although both groups are positive for ANCA antibodies. Unlike COPA syndrome patients, the capillary inflammation and damage in ANCA vasculitis syndrome patients is assumed to be brought about by the autoantibodies. The mechanism of lung inflammation in COPA syndrome is also different from that in patients with SAVI and TMEM-173 gene mutations, which appears to be due to Type-I Interferon dysregulation. The lung involvement in TMEM-173 gene mutation is mostly interstitial, and most of these patients do not present with pulmonary 
Table 1 Genetic mutation, inheritance and disease patterns in different series

\begin{tabular}{|c|c|c|}
\hline Group & Gene mutation, inheritance and family history & Diseases pattern \\
\hline $\begin{array}{l}\text { Watkin et al., } 2015[3] \\
\text { and Tsui et al., } 2018 \text { [2] } \\
(n=21)\end{array}$ & $\begin{array}{l}\text { Mutations: } \\
\text { c.698G > A p.Arg233His, } \\
\text { c.728A > G p.Asp243Gly, } \\
\text { c.721G > A p.Glu241Lys, } \\
\text { c.690G > T p.Lys230Asn. } \\
\text { Four missense mutations in exons } 8 \text { and } 9 \text { of the COPA } \\
\text { gene. } \\
\text { Heritance: Autosomal dominant. } \\
\text { (c.721G > A), (c.728A > G) and (c.698G > A) mutations: } \\
\text { Mostly incomplete penetrance but showed complete } \\
\text { penetrance over two generations in only one family. } \\
\text { (c.690G > T) mutation: Inconclusive regarding } \\
\text { penetrance (carrier is just } 1 \text { year old and is } \\
\text { asymptomatic at this point) }\end{array}$ & $\begin{array}{l}\text { 20/21 (95\%) had Polyarthritis, 21/21 (100\%) had a } \\
\text { progressive pulmonary disease. } \\
4(19 \%) \text { patients had an immune-mediated renal } \\
\text { disease. } \\
\text { Two families with c.721G > A p. Glu241Lys mutation did } \\
\text { not have renal disease. } \\
\text { One patient had a recurrent nonspecific rash. }\end{array}$ \\
\hline $\begin{array}{l}\text { Brynjar O. Jensson, et al. } 2017 \text { [4] } \\
(n=3)\end{array}$ & $\begin{array}{l}\text { Mutation: c. } 721 \mathrm{G}>\text { A p. Glu241Lys. } \\
\text { Heritance: Index case had de novo mutation as both of } \\
\text { his parents were negative for gene mutation and were } \\
\text { healthy at the time of writing. } \\
2 / 3(66 \%) \text { had autosomal dominant with complete } \\
\text { penetrance. }\end{array}$ & $\begin{array}{l}3 / 3(100 \%) \text { had polyarthritis. } \\
3 / 3(100 \%) \text { had a progressive pulmonary disease. } \\
\text { No renal involvement. } \\
1 / 3(33 \%) \text { had nail clubbing. }\end{array}$ \\
\hline $\begin{array}{l}\text { Brennan MA. et al. } 2017 \text { [8] } \\
(n=1)\end{array}$ & $\begin{array}{l}\text { Mutation: } \\
\text { c.727G > A/p. Asp243Asn. Substitution in exon-9. } \\
\text { Heritance: De novo mutation. } \\
\text { No family history but parental genetic status not } \\
\text { available. }\end{array}$ & $\begin{array}{l}\text { 1/1 (100\%) -had erosive destructive Poly JIA at age } 30 \\
\text { months of age as presentation. } \\
\text { At age } 6 \text { years, presented with progressive restrictive } \\
\text { lung disease } \\
\text { Positive for CF gene test [CFTR: genotype F508del/ } \\
\text { R117H(7 T). Sweat chlorides } 52 \text { and } 38 \text { mmol/L], } \\
\text { GERD (needed fundoplication) Developed Systemic } \\
\text { Lupus Erythematosus later in the disease course. } \\
\text { Developed MAS. No renal disease. Positive for finger } \\
\text { clubbing }\end{array}$ \\
\hline $\begin{array}{l}\text { Volpi S et.al. } 2018 \text { [7] } \\
(n=1)\end{array}$ & $\begin{array}{l}\text { Mutation: c.698GNA. } \\
\text { Heritance: Autosomal dominant with variable } \\
\text { penetrance. } \\
\text { Mother of the index case was identified to be an } \\
\text { asymptomatic carrier of same gene mutation. }\end{array}$ & $\begin{array}{l}\text { Presented with progressive severe destructive } \\
\text { polyarthritis } \\
\text { Years later presented with progressive restrictive } \\
\text { pulmonary diseases. No pulmonary hemorrhage or } \\
\text { hemoptysis. } \\
\text { No renal disease. }\end{array}$ \\
\hline Patwardhan A et al. & $\begin{array}{l}\text { Mutation: c.722A > C p, Glu241Ala. } \\
\text { Heritance: Autosomal dominant with complete } \\
\text { penetrance. Son-the index case and his father. } \\
\text { Sibling of the index case is negative for mutation. }\end{array}$ & $\begin{array}{l}\text { 2/2 (100\%)-Presented with progressive mixed } \\
\text { obstructive and restrictive lung disease, chronic } \\
\text { respiratory insufficiency, cough, oxygen requirement, } \\
\text { artificial ventilation, pulmonary hemorrhages. } \\
1 / 2(50 \%) \text { - Father had arthralgias and later developed } \\
\text { destructive polyarthritis. } \\
0 / 2(0 \%) \text {-No renal disease }\end{array}$ \\
\hline
\end{tabular}

NB: (CF Cystic Fibrosis, MAS Macrophage activation syndrome. JIA Juvenile idiopathic arthritis. ENA Extractable nuclear antibodies. DLCO Diffusing capacity of the lungs for carbon monoxide. GERD Gastroesophageal reflux disease. Tsui JL.et al. group had common patients with Levi B Watkin et al. group but had more detailed information on pulmonary symptoms

hemorrhage [5]. The COPA syndrome patients are also different from the patients with STING-associated vasculopathy in which patient mostly presents at infancy (SAVI).

Traditionally, the pulmonary disease and pulmonary hemorrhages are always present in COPA patients and mostly occur early in the disease course as the presenting symptom. Despite immunosuppressive therapy, the pulmonary aspect of the disease is believed to be progressive, and a negative prognostic factor. The majority of the reported patients had pulmonary hemorrhage before their fifth birthday (Table 2). The pulmonary hemorrhage ranges from being insidious to massive lifethreatening hemoptysis requiring ventilatory support.
The pulmonary disease could be restrictive, obstructive or mixed (obstructive + restrictive) in nature.

The unique and specific CT chest finding in COPA patients are diffuse ground-glass opacities, septal fibrosis/thickening and, peripheral patchy hyperinflammation and presence of cysts in parenchymal spaces. The histopathology of the lung biopsy shows capillaritis, follicular bronchiolitis, perivascular neutrophilic cuffing of vessels, capillary wall necrosis (capillaritis), red cells and hemosiderin-laden macrophages. Follicular bronchiolitis is defined as hyperplastic lymphoid follicles infiltrating the small airway walls and interstitium with hyperplastic germinal centers which occur with or without peripheral small cyst formations/emphysema. The lung biopsies 


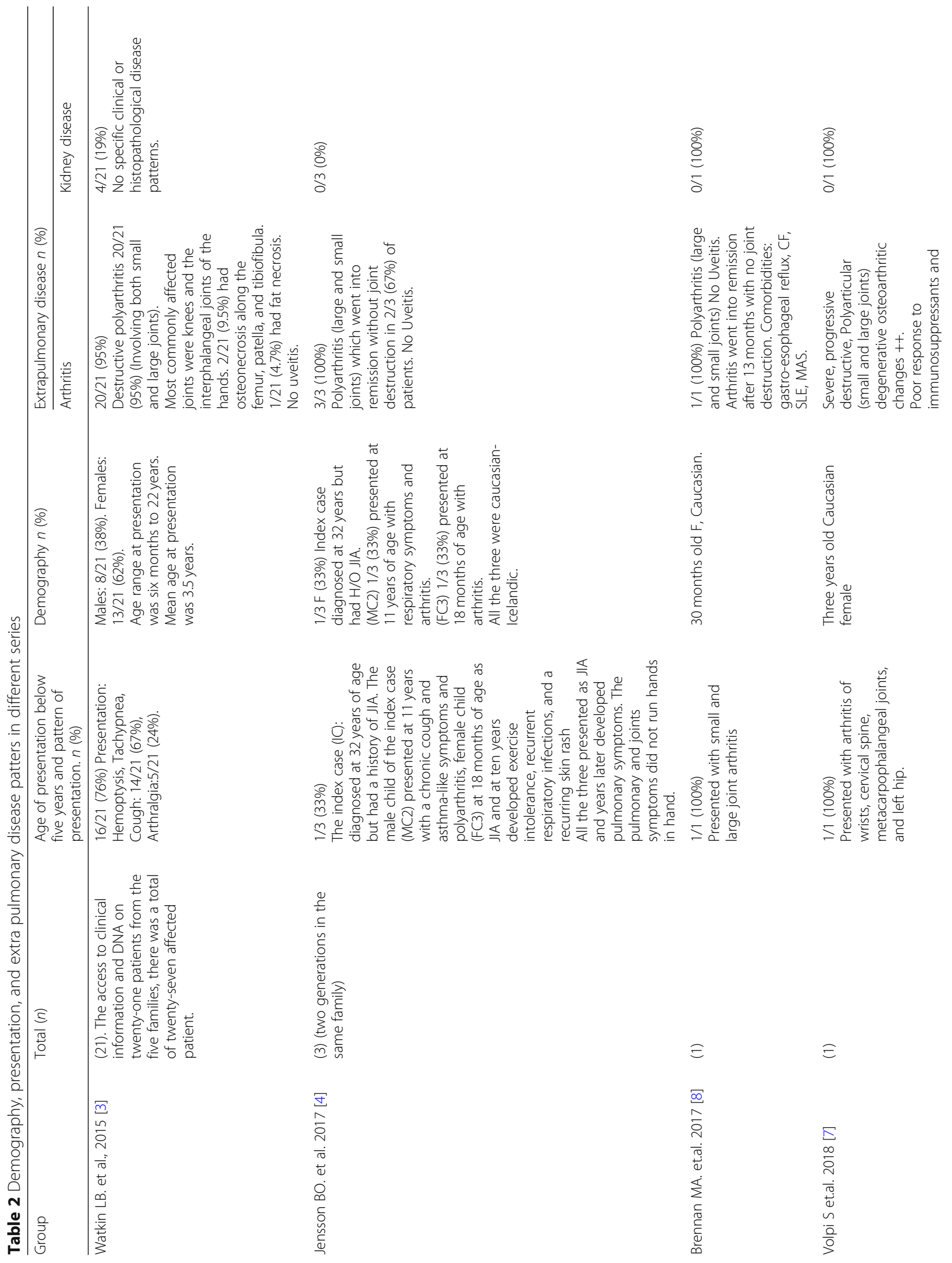




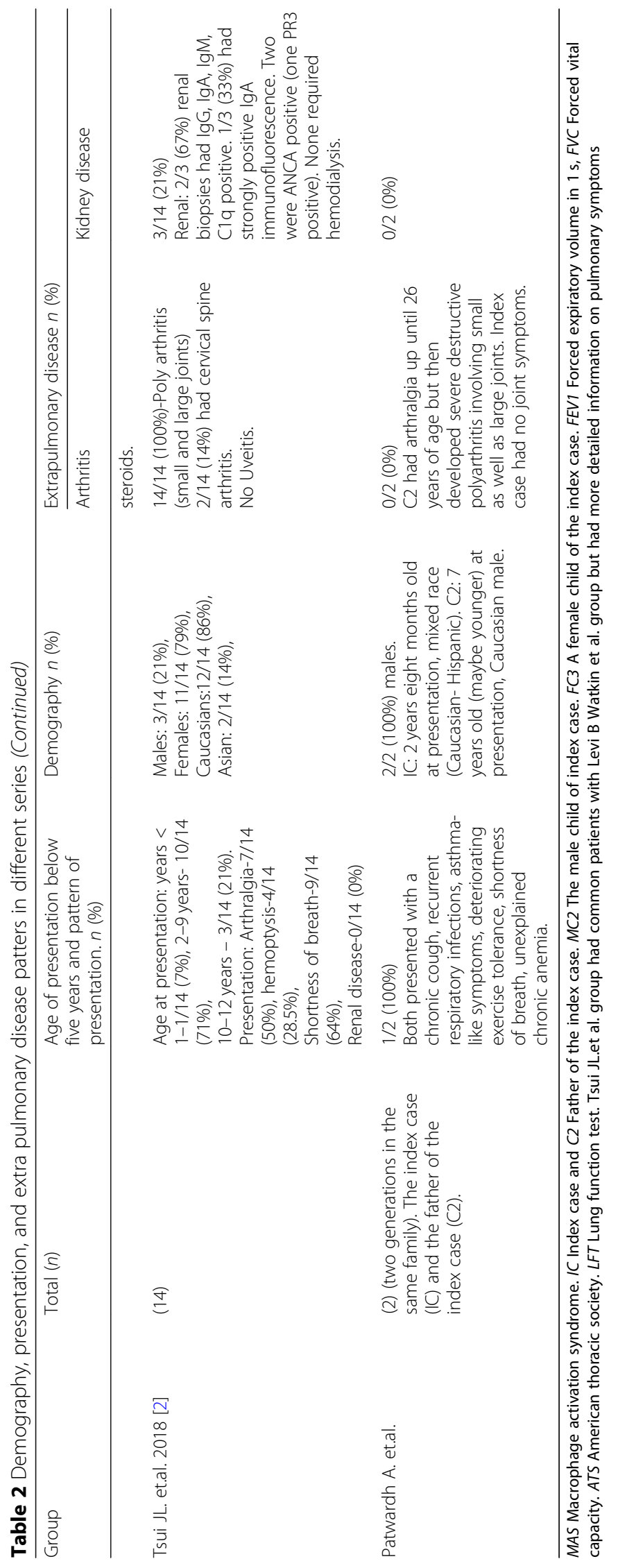




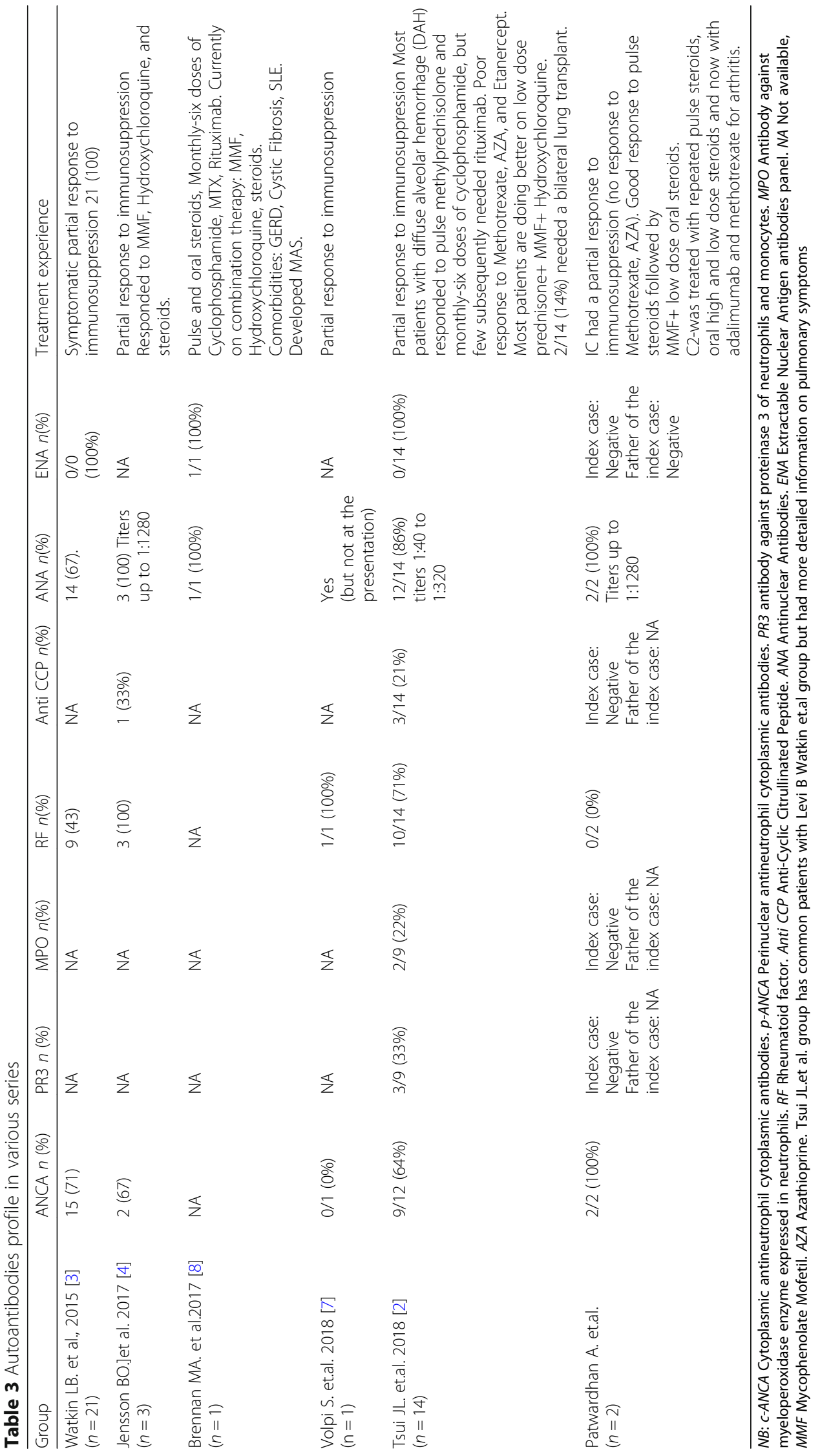




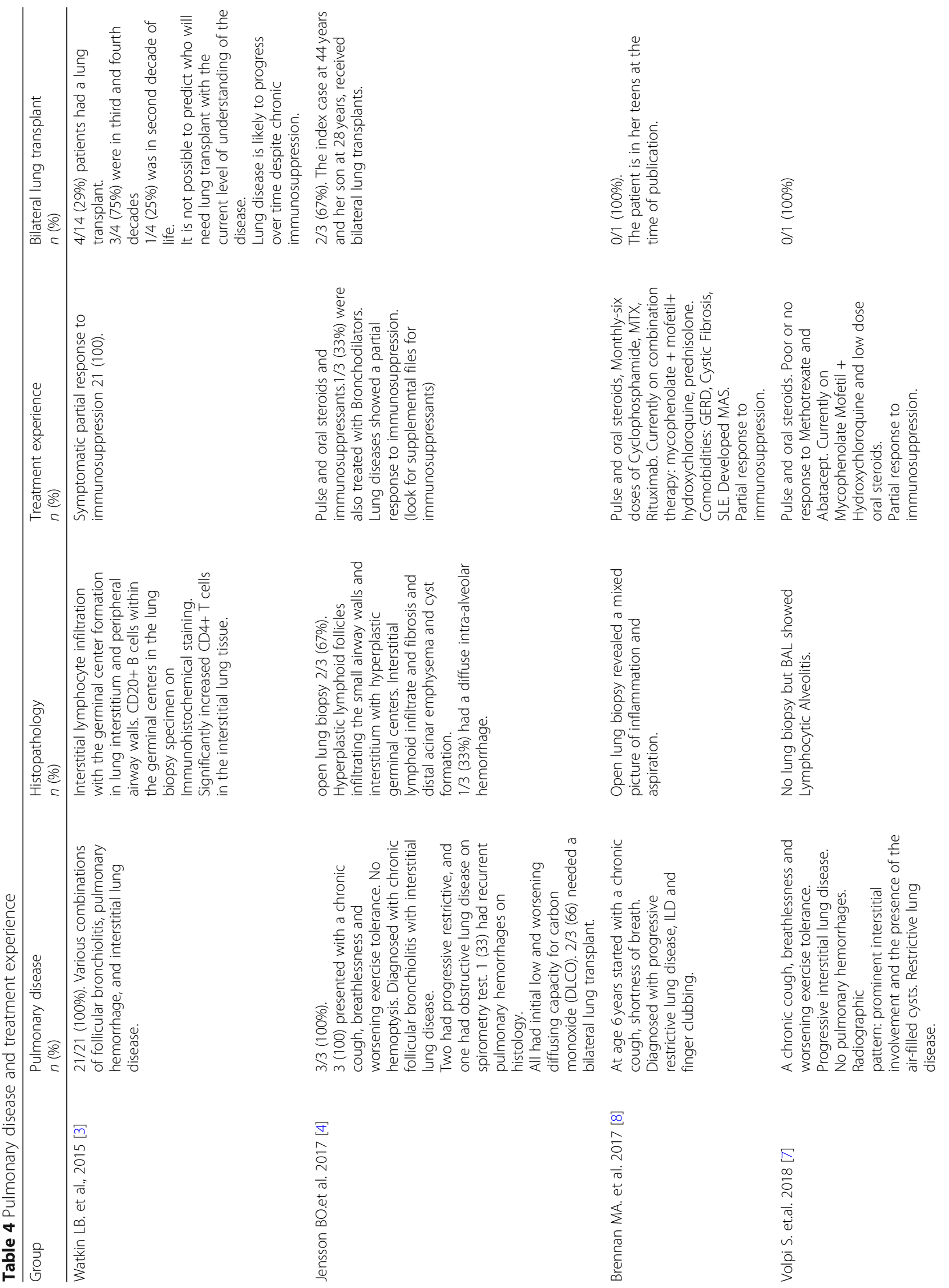




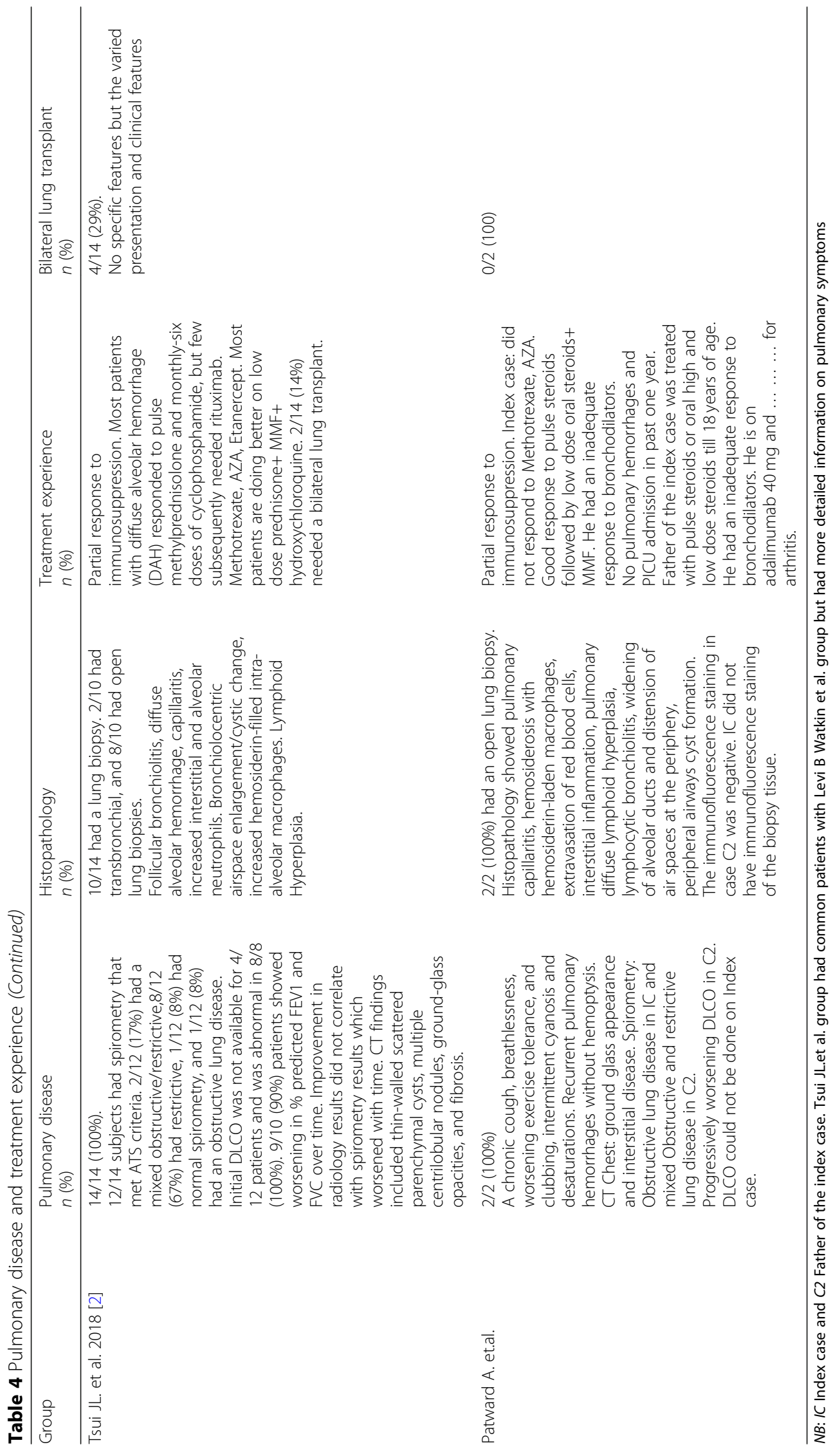


show deposits of hemosiderin suggesting chronic hemorrhages. The majority of patients showed a trend of progressive reduction in total lung capacity, tidal volume and carbon monoxide diffusion capacity. A percentage of the reported patients (2/3 in Jensson et al. and 4/ 21 in Levi B Watkin et al. series) needed a bilateral lung transplant, though the Jensson et al. and Levi B Watkin et al. series have several overlapping patients and may represent the same patients.

The significant interstitial lung disease is usually a later manifestation and seen in their second decades of life. The cystic lesions are reported to increase, and ground glass picture on $\mathrm{CT}$ chest showed a reduction over time suggesting progressive restrictive lung disease. Immunohistochemical staining of lungs shows CD20+ B cells and $\mathrm{CD} 4+\mathrm{T}$ cells infiltration. Due to a limited number of patients with the diagnosis and availability of patchy retrospective data, no accurate predictions can be made about the prognostic markers for lung disease or predict which patients may need a lung transplant in the future. Although follicular bronchiolitis is not specific to COPA syndrome and can be found in several other autoimmune, immunodeficiency, and connective tissue diseases, it is the most common histopathology consistently reported in COPA syndrome patients. In our case series, both the index case and his father had recurrent pulmonary hemorrhages and progressive lung disease but did not have hemoptysis. They had typical CT (W/O contrast) and histologic features as described in other reported cases. Their acute symptoms responded to pulse methylprednisolone.

\section{Musculoskeletal symptoms}

Severe arthralgia is a common finding, but polyarticular erosive arthritis is also reported in many patients with COPA syndrome as a presenting symptom or early in the disease course (Table 2). Arthritis involved large joints as well as small joints. Temporomandibular (TMJ) involvement is not reported in these patients. In one series, $43 \%$ of patients had rheumatoid factor positive arthritis while in another series few patients had anticyclic citrullinated peptide antibody (anti-CCP) positive [5]. It is not clear if anti-CCP and RF antibodies have the equal and same prognostic and diagnostic significance as they have for juvenile idiopathic arthritis (JIA) patients. The joint diseases and pulmonary symptoms are not always reported to go hand in hand, i.e., the flares or remissions of lung and joint disease do not always coincide with each other. In our case series, both the index case and his father did not have arthritis at presentation. Although the father of the index case had recurrent, brief episodes of arthralgia and morning stiffness for initial 4 years of his disease course, he was seen several times by the rheumatologist (not a pediatric rheumatologist) but never at any point diagnosed with arthritis. He later at the age of 26 years presented with destructive polyarthritis.

\section{Kidney disease}

COPA patients are reported to run an increased risk for a heterogeneous nonspecific autoimmune renal disease. In a published series of 21 patients, $44 \%$ had either abnormal renal function and or had proteinuria (Table 2). The six patients who had been reported with renal biopsy data showed abnormal but variable patterns of histopathology 1. None of the patients with c.721G > A p.Glu241Lys mutation had renal disease suggesting that this mutation may be protective for renal disease. Our index case presented at 2 years 8 months of age and his father presented at 7 years of age. Currently, the index case is 5.5 years old, and his father is 29 years old. Both of our patients did not have renal disease any time in their diseases course.

\section{Prognosis}

Longitudinal data (5 to 20 years) on five patients from Levi B Watkin et al. series [3] and three from Jensson et al. series [4] showed that despite treatment with immunosuppressants and steroids therapy, their disease progressed, and five $(24 \%)$ from Levi B Watkin et al. series [3] and $2(66.6 \%)$ from Jensson et al. series [4] needed bilateral lung transplants. They all received different and practice-based immunosuppressant therapy, and their compliance is not included in the comparative analysis. The immunosuppressant therapy showed a symptomatic response in most of the COPA syndrome patients but did not necessarily affect the long-term outcome. The lung function tests, especially DLCO, continued to show progressive worsening with time in most cases. Most researchers believe that the lung disease may continue to progress despite immunosuppressive treatment and immunosuppression may not affect the long-term course of the disease. The researchers could not identify the markers which can inform as to which patients may need lung transplants in the future. The patients who received transplants had presented early in their lives suggests that early onset of the disease may be an adverse prognostic factor. All these patients were treated differently due to diagnostic uncertainties and ignorance about COPA entity; therefore, comparison of the disease course and treatment responses for different gene mutations is difficult.

\section{Conclusion}

The available information on COPA gene mutation and the associated syndrome is not enough to predict the course of the disease but is enough to recognize the symptoms and diagnose it early. COPA syndrome may be new and a quite diverse disease but it may not be that 
uncommon [8]. Sharing the new mutations and clinical aspects is crucial to the development of better treatment plans using pragmatic research to optimize the management options.

\section{Abbreviations}

CANCA: Anti-neutrophil cytoplasmic antibody; COPA: Coatomer Protein, Subunit Alpha; DLCO: Diffusing capacity or transfer factor of the lung for carbon monoxide.; MPO: Anti-myeloperoxidase antibodies;

pANCA: Perinuclear antineutrophil cytoplasmic antibody; PICU: Pediatric intensive care unit; PR3: Anti-proteinase-3 antibodies; RF: Rheumatoid factor; SOB: Shortness of breath

\section{Acknowledgments}

I acknowledge the help of Dr. L. Gozal MD, in reviewing the manuscript. The author would like to thank Charles H Spencer, MD for his editorial assistance in copywriting.

\section{Informed consent}

Patient consent is taken for acceptance for publishing the case series and publishing the unmasked pictures of both the patients. Institutional review board approval is obtained for the case series reporting.

\section{Authors' contributions}

Equal contribution in writing up the report and editing the manuscript. Both authors read and approved the final manuscript.

\section{Funding}

No funding obtained.

\section{Availability of data and materials}

Is available.

\section{Ethics approval and consent to participate}

Ethical Approval from IRB is obtained and patient/parent consent to publish their photographs and clinical information is obtained.

\section{Consent for publication}

Consent for publication is obtained from the patient/parents.

\section{Competing interests}

The authors declare that they have no competing interests.

\section{Author details}

'University of Missouri School of Medicine, 400 Keene Street, Columbia, MO 65201, USA. 'University of Mississippi Medical Center, Batson Children's Hospital, Rm 289, 2500 North State St, Jackson, MS 39216, USA.

Received: 5 June 2019 Accepted: 7 August 2019

Published online: 27 August 2019

\section{References}

1. Chow VT, Quek HH. HEP-COP, a novel human gene whose product is highly homologous to the alpha-subunit of the yeast coatomer protein complex. Gene. 1996;169(2):223-7.

2. Tsui IL, Estrada OA, Deng Z, Wang KM, Law CS, Elicker BM, et al. Analysis of pulmonary features and treatment approaches in the COPA syndrome. ERJ Open Res. 2018;4(2):00017-2018. https://doi.org/10.1183/23120541.00017-201 8.

3. Watkin $L B$, Jessen B, Wiszniewski W, Vece TJ, Jan M, Sha Y, et al. COPA mutations impair ER-Golgi transport and cause hereditary autoimmunemediated lung disease and arthritis. Nat Genet. 2015;47(6):654-60.

4. Jensson BO, Hansdottir S, Arnadottir GA, Sulem G, Kristjansson RP, Oddsson $A$, et al. COPA syndrome in an Icelandic family caused by a recurrent missense mutation in COPA. BMC Med Genet. 2017;18(1):129.

5. Vece TJ, Watkin LB, Nicholas S, Canter D, Braun MC, Guillerman RP, et al. Copa syndrome: a novel autosomal dominant immune Dysregulatory disease. J Clin Immunol. 2016;36(4):377-87.

6. de Jesus AA, Goldbach-Mansky R. Newly recognized Mendelian disorders with rheumatic manifestations. Curr Opin Rheumatol. 2015;27(5):511-9.
7. Volpi S, Tsui J, Mariani M, Pastorino C, Caorsi R, Sacco O, et al. Type I interferon pathway activation in COPA syndrome. Clin Immunol. 2018;187:33-6.

8. Brennan M, McDougall C, Walsh J, Crow YJ, Davidson J. 013. COPA syndrome - a new condition to consider when features of polyarthritis and interstitial lung disease are present. Rheumatology. 2017;56(suppl_6):kex356.059

9. Lek M, Karczewski KJ, Minikel EV, Samocha KE, Banks E, Fennell T, et al. Analysis of protein-coding genetic variation in 60,706 humans. Nature. 2016;536(7616):285-91.

10. Kobayashi Y, Yang S, Nykamp K, Garcia J, Lincoln SE, Topper SE. Pathogenic variant burden in the EXAC database: an empirical approach to evaluating population data for clinical variant interpretation. Genome Med. 2017;9(1):13.

11. Tanjore H, Blackwell TS, Lawson WE. Emerging evidence for endoplasmic reticulum stress in the pathogenesis of idiopathic pulmonary fibrosis. Am J Physiol Lung Cell Mol Physiol. 2012;302(8):L721-9.

12. Olewicz-Gawlik A, Danczak-Pazdrowska A, Kuznar-Kaminska B, GornowiczPorowska J, Katulska K, Trzybulska D, et al. Interleukin-17 and interleukin-23: importance in the pathogenesis of lung impairment in patients with systemic sclerosis. Int J Rheum Dis. 2014;17(6):664-70.

13. Weaver $C T$, Elson CO, Fouser LA, Kolls JK. The Th17 pathway and inflammatory diseases of the intestines, lungs, and skin. Annu Rev Pathol. 2013;8:477-512.

14. Leipe J, Grunke M, Dechant C, Reindl C, Kerzendorf U, Schulze-Koops H, et al. Role of Th17 cells in human autoimmune arthritis. Arthritis Rheum. 2010; 62(10):2876-85

15. Miossec P, Korn T, Kuchroo VK. Interleukin-17 and type 17 helper T cells. N Engl J Med. 2009;361(9):888-98.

\section{Publisher's Note}

Springer Nature remains neutral with regard to jurisdictional claims in published maps and institutional affiliations.

\section{Ready to submit your research? Choose BMC and benefit from:}

- fast, convenient online submission

- thorough peer review by experienced researchers in your field

- rapid publication on acceptance

- support for research data, including large and complex data types

- gold Open Access which fosters wider collaboration and increased citations

- maximum visibility for your research: over $100 \mathrm{M}$ website views per year

At BMC, research is always in progress.

Learn more biomedcentral.com/submissions 